\title{
Microaggression and Diversity: Tracing Indonesian University Students' Attitudes toward Pluralism through Metaphorical Creative Expressions
}

\author{
Andreas Akun \& Wiwik Andreani \\ Bina Nusantara University, Indonesia
}

\begin{abstract}
This is a library study of university students' instant poems about their attitudes toward pluralism in Indonesia. The goals of the study are to identify the tones of the poems and then trace the microaggressive attitudes toward pluralism through the metaphorical expressions found in the poems. The study of the poems has revealed that microaggressions may take diverse unrealized forms, such as seeing difference as wrong or sinful, considering the "rainbow" of diversity as piteous, viewing intermingled mixtures of different backgrounds with ambiguous attitudes, the impossibility of having a real sense of "we" belonging, fictiveness of superior ethnicity and both sides of microaggression, disempowering diversities with too many differences, merely teaching and telling of diversity without modeling, surfacing of microaggressive domination, and questioning the fiction of authentic ethnicity. All issues have been proven to be the new faces of modern and subtle racism and chauvinism with their growing underground power to reject diversity.
\end{abstract}

Key Words: Pluralism, microaggression, metaphor, attitude, poetry

\section{INTRODUCTION}

Our previous study of five university students of English Department in Jakarta and surrounding has shown prospectively positive result, where out of 153 sampling participants, most of them (65\%) have positive attitude toward pluralism issue in Indonesia. Only a small number of them (16\%) who have negative attitude and $19 \%$ of them are neutral or ambiguous (Akun \& Andreani, 2015). However, the everyday reality still shows us that problems of pluralism in this country keep emerging where intolerance and prejudice of other groups with different backgrounds keep surfacing at the same time. The latest issue-without forgetting the most tragic 1998 racial tension or 1965 political riot-is the Tolikara incident where a number of Christian people were reported to ban Muslims from praying and celebrating Idul Fitri at the end of the fasting month.

Based on this background, it is challenging to delve into the root of the problems, resting in the reasons why people have negative or ambiguous attitudes toward pluralism reality. Thus, this study centers around the problems of negative attitudes, and more specifically portrays the microaggression as captured both directly and indirectly in the students' creative and poetic expressions. The study will be limited to 111 English Department students from three universities i.e. Bina Nusantara University Jakarta (53 participants, private university, non-ideological), University of Indonesia Depok (38 participants, state university), and Maranatha Christian University Bandung (20 participants, private university, under a certain religious ideology). Specifically, the study will be focused on the negative and ambiguous/neutral attitudes from the students to trace their everyday 
experience in dealing with pluralism issues. The three universities have sufficiently represented diverse backgrounds for the students to reflect diversity experiences.

\section{DIVERSITY AND MICROAGGRESSION}

To better understand of people's attitude toward pluralism, indirect spontaneous expressions may help in a significant way as it gives a deeper look into the root of the surfacing diversity realities. Probing the tones and metaphorical expressions can be one option worth consideration for this purpose, and this study attempts to show the possible findings among the young intellectuals. The concepts of diversity, micro-aggression, and tone in poetry are on the first place provided to examine the issue of pluralism-one $\mathrm{i}^{\mathrm{i}}$ fundamental issue raised from the beginning of this country establishment until today.

Diversity, simply defined, is 'the quality of being different...derived from 'diverse' meaning differing from one another, or simply composed of distinct elements or qualities"(Parvis, 2013: 13). The key word is 'difference' as something absolute and the essence of discussing diversity to date is to keep learning how to accept these differences to live harmoniously among others as social beings. There are many types of diversity such as "culture, ethnicity, class, gender, religion, age, ability, language, weight, style, idea, income, orientation, geographic location, and many more aspects which make people unique" (p. 15). The diversity discussed in this study covers race, ethnicity, religion, culture, and social class. The issues are explored through the negative and pessimistic responses depicted in the students' poems. We assume that this dark side discussion - as opposed to the positive responses-may provide a more comprehensive look of the matter and may help finding the best attitudes to be strengthened especially through diversity education.

The attitudes toward pluralism is not always direct and observable, and the experience of marginalizing and being marginalized in the plural society when number counts is also subtle and even consciously unintended. In everyday life, the negative attitudes addressed to the minority by the majority and vice versa may result in microaggressive attitudes when they subtly happen beyond awareness or consciousness of both sides. Specifically, according to Sue (2010) these negative attitudes are characterized by "brief and commonplace daily verbal, behavioral, and environmental indignities, whether intentional or unintentional, that communicate hostile, derogatory, or negative racial, gender, sexual-orientation, and religious slights and insults to the target person or group" (p. 5). Most of the time the perpetrators are unintentional or unaware of their involvement in committing the microagrgessions, and that is why attention to this matter needs more effort to make everyone aware of the deeds. Further, Sue (2010) has focus more on microaggressions in everyday life covering race, gender, and sexual orientation. He has divided racial microaggression into three: individual racism, institutional racism, and cultural racism. Firstly, individual racism is "overt, conscious, and deliberate individual acts intended to harm, place at a disadvantage, or discriminate against racial minorities. Serving Black patrons last, using racial epithets, preventing a White son or daughter from dating or marrying a person of color, or not showing clients of color housing in affluent White neighborhoods are all examples" (p. 7). It is obvious that this type of racism is more individual or personal developing out of this smaller scope of individual dynamics including hate crimes at their extreme ends. Secondly, institutional racism constitutes,

"any policy, practice, procedure, or structure in business, industry, government, courts, churches, municipalities, schools, and so forth, by which decisions and actions are made that unfairly subordinate persons of colors while allowing other groups to profit from the outcomes...include racial profiling, segregated churches and neighborhoods, discriminatory 
hiring and promotion practices, and educational curricula that ignore and distort the history of minority" (pp. 7-8).

Lastly, cultural racism is

"the most insidious and damaging form of racism...defined as the individual and institutional expression of the superiority of one group's cultural heritage (arts/crafts, history, traditions, language, and values) over another group's, and the power to impose those standards upon other groups...For example, Native Americans have at times been forbidden to practice their religions ('We are a Christian people') or to speak in their native tongues ('English is superior'), and in contemporary textbooks the histories or contributions of people of color have been neglected or distorted ("western history and civilization are superior')" (p. 8).

Sue has also emphasized that racism today has a new face with its more contemporary and insidious presence, becoming "invisible, subtle, and more indirect, operating below the level of conscious awareness, and continuing to oppress in unseen ways" with new names such as symbolic, modern, implicit, or aversive racism (2010: 8-9). The last racism is strictly connected to the concept of microaggression where the perpetrators believe that they are not racist, "nonprejudiced, espouse egalitarian values, and would never consciously discriminate, but they, nevertheless, harbor unconscious biased attitudes that may result in discriminatory actions" (p. 9).

The effects of microaggression are not only individual and psychological, but also impactful on the quality and standard of life of the marginalized group, and finally the impacts operate on systematic and macro level such as "denying equal access and opportunity in education, employment, and health care" (p. 16) and these effects are tremendous in a certain way so that the only way to end them is by denying or erasing microaggression from its being "hidden, invisible, unspoken, and excused as innocent slights with minimal harm" (p. 19). Thus, in this study context, exposing the microaggression operating in the students' attitudes by identifying them and exploring the backgrounds is a way to actualize this purpose.

\section{POETRY AND NEGATIVE METAPHORICAL TONE}

Tracing the attitude toward pluralism is not always easy, especially from those of young intellectuals because negative reaction toward pluralism rooting for example from racism with its new faces nowadays is not open or direct but subtle and hidden. In the light of this intricacy, a literary medium of expression such as poetry with its nature of indirectness can help much in revealing what is actually "speaking" in the oblique and metaphorical expressions. William Wordsworth has long put forward the idea of spontaneity and tranquility in poetry creation-two seemingly opposite sideswhile both are psychological and emotional dynamics when someone witnesses or experiences reality. Spontaneity indicates "spontaneous overflow of powerful feelings", an instant pouring out of emotions for or against the reality, while tranquility requires time and contemplation of the reality. The process of poetic creation accommodates both sides because the produced expressions are actually recollected from highlights of the past good or bad experiences-all residing in the mind-triggered by the present or recent momentum just before the creation.

"These feelings do not at once lead to the creation of poetry; they are recalled by the poet after the actual situation which first aroused them is past...Poetry...takes its origin from emotion recollected in tranquility: the emotion is contemplated till by a species of reaction the tranquility gradually disappears, and an emotion, similar to that which was before the 
subject of contemplation, is gradually produced, and does itself actually exist in the mind". (Brett \& Jones, 2005: xlv-xlvi).

The question of originality and purity of emotions and feelings is also emphasized by Wordsworth where he spoke of modified emotional responses reflected in the resulted expressions. Modification signifies impurity and unoriginality, thus a poem is naturally resulted from modified emotions fitting the poet's background, intention, and ideology, and accordingly appropriation is an essential mechanism in the production: "...our continued influxes of feeling are modified and directed by our thoughts and our thoughts are indeed the representatives of all our past feelings" (Brett \& Jones, 2005: xlvi). This study has specifically combined the idea of spontaneity and tranquility in a poem production where a poem-though written instantly for more original or genuine attitudes ${ }^{\mathrm{ii}}$ - is a medium of expression of crystallized ideas and attitudes that have long enough inhibited the writer's mind. The participants are then instantly asked to freely write down their thoughts or ideas on pluralism reality into a free poem and submit the result afterward. All participants are English Department students who have studied or at least been introduced to poetry (through subjects such as Poetry Analysis and Introduction to English Literature) so that they know how to express themselves in a literary way and understand literary expressions. They are given around 30-45 minutes to write the poem related to their real life experience on pluralism, especially on how they take side and take a positive, negative, or neutral/ ambiguous attitude over this pluralism issue. Besides, literary expressions - whether symbolical or metaphorical-help tracing the intended attitudes because this pluralism issue is somehow sensitive to a certain extent to be openly talked about, particularly issues on religion and race or ethnicity. Therefore, learning the indirect metaphorical or symbolical expressions, thus their attitudes, is of importance. Moreover, observing the fact that unsympathetic attitudes toward pluralism-specifically regarding ethnicity-is still coloring Indonesian people's everyday interaction, then there is a reasonable worry that certain groups of people from certain ethnic groups still think that theirs are superior or the best, rejecting the modern and postcolonial thinking of celebrating hybrid ethnic identity. This way of thinking is against modern realities where diversity is inevitable and hybrid interaction is an unavoidable dynamism to harmoniously survive in this era. More dangerously, as emphasized by Heryanto (2014), the belief that certain ethnicities are more superior or better with its impactful (negative rather than positive) consequences is fictitious because it is based on something "fundamentally, though not entirely, a fiction" (p. 134) just like stories in films. The same concept of fictitiousness applies to Indonesian "Communism" since 1966, Indonesian "Chineseness", or "Islam" after 9/11 in various parts of the world. This postmodern concept of identity or ethnicity as fiction advocates the idea that purity or originality is merely imaginary and impossible to be defined in "any purely objectivist and materialist fashion" because the imagined reality is always fluid and fragmentary, and thus unmanageably possible to be delineated and defined in an objective, factual, wholly, and nonfictitious way. This is contrary to the common belief-perhaps still growing prosperously in Indonesian context-that "the fiction precedes and invents the real" (p. 134), that the real is fabricated and created based on the fiction developing in people's imagination of purity or originality. Further, Heryanto has shown his concern - in an interview by in Kompas Daily, 2 August 2015- thatbeyond Indonesian greatness and diversity, there are groups of modern isms which foster intolerance toward hybrid identity and impurity, believing in and celebrating purity-originality, looking down at and attacking others considered as impure or hybrid. Sadly, this is practiced by some modern religions and ideologies. Meanwhile, becoming hybrid and being aware of its existence will not be able to eliminate social inequality, but hybridity is seen to have the potential and attraction to be a medium of resistance. This resistance can be considered as a struggle and fight 
against the huge oppression and domination in the name of fiction about authentic, original, and pure identity (Heryanto, 2015).

Metaphor, according to Modell (2005) is defined

"as a cognitive tool that enables the transfer of meaning between dissimilar domains...the Greek term metaphora literally means 'transfer'...Metaphor retains a paradoxical quality in that there is an "as-if" play of similarity and difference and not a rigid specified identity of meaning. As metaphor enables the transfer of meaning between dissimilar domains, transference repetition, the similarity of affective responses between the differing domains of the past and the present can be understood as a metaphoric process" (p. 562).

How can metaphor help in understanding reality expressed in literature? Fainsilber and Ortony (1987: 240-241) have put forward three communicative functions of metaphor in a close relation to three restrictive hypotheses listed as inexpressibility, compactness, and vividness. Firstly, metaphor enables a person to express an idea hard, problematic or even impossible to be expressed in an ordinary or literal language usage. Thus, when the idea may not be expressible in a usual way, metaphor then functions to represent the idea. Secondly, the role of metaphor is to "convey a great deal of information succinctly" due to its essence as a solid means of communication. Metaphor may for example merely use a word to communicate and reveal a huge idea. Thirdly, through metaphors, a comprehensive image and representation of event or idea can be summarized because it "may help capture the vividness of phenomenal experience...they can pain a richer and more detailed picture of our subjective experience that might be expressed by literal language". Metaphor enables someone to more accurately communicate an unclear, ambiguous, or even contradictory idea in a single expression.

There are at least three functions of language (Arp, 1998: 561-2) i.e. its practical use as a tool for communicating information, its literary use as a medium of sharing important experience by letting others inspirationally partake in it, and its hortatory use as an instrument for persuasion. For its literary use of language, imagination is at use because only though imagination someone is capable

"to live more fully, more deeply, more richly, and with greater awareness...by broadening our experience... by making us acquainted with a range of experience... or by deepening our experience-that is by making us feel more poignantly and more understandingly the everyday experiences all of us have" (pp. 563-4).

Lastly, tone itself is defined as

"the emotional spin a poet puts on his words; the edge or attitude in the voice of a poem...the coloration of the words, their shading, their warmth or coolness - as in painting. It is also how they sound, their pitch (high or low), harmony (sweet or shrill), and volume (loud or soft)—as in music" (Drury, 2006:322).

In short, it is the attitude the poet takes toward a theme or a subject (Kennedy \& Gioia, 2005:717).

\section{MICROAGGRESSION: BEYOND PLURALISM}

In our previous study of students' attitudes toward pluralism in Indonesia (see Akun \& Andreani, 2015), we have found out that most of the students have shown their positive attitude $(65 \%)$. 
However, those with neutral/ ambiguous and negative attitudes (35\%) are not insignificant. In this study, out of 111 participants, most participants still have positive attitudes i.e. 59 participants $(53.16 \%)$, while those with negative attitudes are 26 participants $(23.42 \%)$ and the neutral are the same $26(23.42 \%)$. Now, the combination of those with negative attitudes and the neutral ones become bigger i.e. $46.84 \%$, almost half of total amount, and we consider this as significant and thus the focus of this study.

This study will be centered on microaggression and metaphorical expressions used to express subtle negative attitude and experience in facing and coping with pluralism realities. Metaphor, as discussed in our previous study, is dominantly used by the participants. WE have found out that metaphors such as salad, batik, Bhinneka Tunggal Ika (Unity in Diversity), black pearl, cage, circle, clothes, colors, eggs, family, flowers, garden, Garuda (mythical bird as Indonesia's National Symbol), Indonesia, ingredients, jar, journey, music, ocean, one, rain, rainbow, sandals, etc. are rich and strong metaphors to describe experiences on pluralism. In this study, the focus is placed on metaphors signifying the negative or ambiguous/neutral attitudes and how microaggression is reflected through the metaphors and the poems as a whole. 12 poems are chosen for this analysis. They are Different, I Can't Deny, I Had A Friend, One, Pity Rainbow, Pluracism, Pluralism (1), Pluralism (2), Questions, Unity,V ariety Brings Disaster, and You and Me. There are ten metaphors and microaggressions reflected in the instant poems that speak of pluralism beyond its surface, specifically from its undesirable viewpoint.

\section{"Pluracism": Being different as wrong or sin.}

The first metaphor "Pluracism" (1), a combination of pluralism and racism, undesirably sees pluralism as constructed by a dominant power intentionally aiming at separating people based on their colors and religions. The power, named as plural "they" in the poem, can be any existing groups (at least based on race or ethnicity and religion in the poem as it talks about colors and sin), seems to have dividing mission because it tells people to be different, to belong to certain colors or classifications (e.g. religions) and forbid mixed or hybrid interaction with others as they are not good (sinful, wrong). Even worse, the classification makes it clear that it is wrong or sinful to be different as evidently stated here: "We didn't feel any guilt when we say we are different / until they said it is a sin"(Pluracism, lines 5-6) ). The word "sin" obviously signifies religion or belief because only this group uses the jargon and this can be considered as microaggression because people from certain religions or beliefs will feel guilty or sinful if they celebrate difference, accepting others as equal (not worse or better!). "We" as the representation of common citizen actually don't mind at all of the diversity, they don't even realize that it matters to differentiate and separate them from others: "When we even think that we are not different" (Pluracism, line 9). Consequently, "they" (the powerful religions/ethnic groups) have microaggressively segregate people, narrowing "us", ideologically forcing us to have negative image of the plurality of society-thus the metaphor pluracism-and belittling the already broadminded "us" into the trap of unknown essentialism. "Who are they to us?" (line 7) is the question the alienated people ask to the anti-pluralism power (plural but with negative attributes of "-ism"), indicating that they are now confused, narrowed, and unenlightened.

\section{Pity rainbow: separating diversity}

The second metaphor is "Pity Rainbow" (2) that contrastively sees diversity not as beautiful—as normally signified by the metaphor rainbow-but as piteous and sad. This oxymoronic metaphor reveals the triadic opposing realities: the propaganda, the real practice, and the hope. The rainbow is there because different people live in the same one world with the propaganda-in Indonesian 
context, the Bhinneka Tunggal Ika-to be united in unity and peace. However, the real everyday practice is seen as contradictory where "pluralism makes us...separated" (line 8). The slogan that diversity is pretty like different colors of rainbow is proven invalid because the real differences according to the persona "bring unaided conflicts" (line 12). Microaggression takes place because the persona has the hope to be united, but the fact "we are one, but we are apart" (lines 5-7). How come? The fact that the rainbow of diversity in the persona's experience shows that "our differences are pity" (line11) because there are conflicts here and there due to the differences so that the persona sees this as an unfulfilled promise and hope of unity without conflicts. The persona finally sees diversity as separating rather than unifying.

\section{You and Me, but not "we"}

The third metaphor is "we" as showing sense of belonging and domination of the majority over the minority. Similar to the previous poem, the persona in You and Me (3) speaks of living on the same ground and seemingly from the outside united. However, seen from the persona's minority point of view, there is no unity in a deeper level because the persona says, "but there are still you and me, not we" (lines 3-4). You and me are separate individuals living together in a place and in one's own way of life without real acceptance and cross cultural interaction. The persona still feels that he or she is marginalized and does not wholly belong to the community. Why? Because as minority-as the metaphor "small soldier" signifies - the persona microaggressively feels alienated and resisted: "You, put your war on me, You against me" (lines 7-8). This war does not have to be physical since the persona indicates that they live together, side by side with the majority. However, when the persona says that "There is no place for we" (line 5), he/she talks about sense of belonging and acceptance of minority as they really are with their identity. The persona also talks about the missing peace: "Peace is just a left word" (line 6) because of the marginalization. The domination of the majority, metaphorically represented in the word "giant" through the "war" has put the "dwarf" minority with their small soldier helpless and hopeless as depicted in this line "We will never become the true we"(line 12), and this is a clear sign of microaggression where the minority feel desperate of their destiny among the plural society.

\section{A bowl of intermingled salad: Being (im)proper?}

The fourth metaphor is a bowl of salad, associating foods (vegetables, fruits, sauces, etc.) with diversity of society in Indonesia. The poem I Had a Friend (4) describes how two friends have salad for their lunch, taking all foods necessary for the salad and putting them into a bowl, tossing and bathing them with the same amount of sauces, and be ready for the lunch. However, one of the friends takes an empty plate to put aside the taken peas because he does not like them. The other friend asks him why he takes the peas, and then mingling them with other food elements if he dislikes peas. The friend just replies that it seems proper to do so during the food preparation and puts them aside when the real eating procession is done, although the other friend keeps asking whether it is improper to set the peas apart after taking them as if he will eat them. The friend just answers again by stressing that he does not like peas. This illustrative poem questions people's ambiguous attitudes toward diversity as what is seen from outside differs from the inside. Just like the famous American salad bowl, Indonesia as a country is metaphorized as a salad bowl as well where all salad elements (metaphors of diverse communities with their own identities) are intermingled and contained (how diverse people are formally/politically accepted and treated). It is interesting that propriety or impropriety of social behaviors toward pluralism is being questioned. In individual real social life, ambiguity of attitude is clearly seen when the friend at the first place takes the peas, mingles them, but then separate them because he dislikes them. He seems to be socially proper by accepting the peas (one element of diverse societies) but the improperly reject and throw 
them away. The key words showing the real attitude are "I don't like peas" that show a negative attitude toward pluralism. The seemingly ambiguous attitude is finally unambiguous at the end where "dislikes" of certain elements of diverse society still color the menu of daily salad meal. The ambiguity of attitude in its level actually shows microaggression because the elements (most possibly the minorities) of the menu such as peas are politically (read propagandizing or sloganizing in the outside) accepted, but then rejected in the deeper inside level of everyday interaction, even without being consciously known or noticed, for it is hidden in the ambiguity of propriety or impropriety of social behaviors, just like the friend's in the poem. He should have behaved straight by appropriating himself without any "dislikes" to the diverse elements of diversity (i.e. not taking the peas if he is not into them, but respecting and accepting their existence there as to complete menu of others).

\section{Ethnicity and "Chineseness": Both sides of microaggression}

The fifth metaphor is imagined untrue "color" in a poem entitled Unity (5) that plainly reflects issues of ethnicity, minority, and Chineseness in real Indonesian context. This poem shows microaggressive behaviors from both sides: majority and minority. This simple and blunt poemseemingly easy going - actually speaks of serious and bigger problem of pride, prejudice, implied racism and negative attitude toward pluralism. How come? The persona in the first place talks about the fact that being a Chinese in Indonesia is sometimes hard because of her position as minority group. At the same time, the persona raises the issue of ethnicity when sheat the very beginning says "Being a Chinese". Then, another issue of national identity and then racialism is unconsciously raised when she sadly admits that she "can't marry Indonesian" (line 3) because her "parents said so" (line 4) although the men are "handsome, kind, and rich" (line5). What does she mean when she addresses "Indonesian" in the poem? Who is Indonesian? She unconsciously considers herself as not Indonesian; or at least she does not feel that she fully belongs to Indonesia as her national identity. Does this mean that she still retains her Chinese mainland identity? The next question, why can't she marry the Indonesian young man? Who is this Indonesian man? The answer is obviousthough not stated - that the man is anyone else from other ethnic groups, but not Chinese like her. Here the issue of race and ethnicity is unconsciously raised. This is strengthened by the line "Even though they are handsome, kind, and rich" (line 5) which signifies that the prohibition is not based on look (handsomeness), moral and social conduct (kindness), or economy (richness), but most probably based on race (mongoloid) and ethnicity (Chinese)! This is a new face of racism where an individual does not fully realize that she or he practices dislikes over other races or ethnic groups.

The microaggressive behaviors are shown in the poem as coming from both sides. From the minority standing point, the persona justifies her attitude (does not marry "Indonesian") because her parents say so, and sadly she agrees by saying "But it's alright" (line7) even though she has a dream to be really "one" and "united" as Indonesian without "prejudice" and "pride" (lines 9-10). The persona's justification above and her acceptance of her parents' attitude actually reveal that she still practice pride and prejudice as a form of microaggrssion. Meanwhile, from the majority point of view, the "hardship" of being a Chinese minority in Indonesian context - though without example in the poem - is real, especially during the era of persona's father (New Order) as elaborated by Ariel Heryanto (2014: 133) as politics of exclusion where the Chinese ethnic group have been marginalized and excluded in many ways such as specifically-coded ID card, exclusion from public leadership, erasure of history concerning Indonesian Chinese contribution to national independence, etc. These political exclusions have direct or indirect impacts on Chinese ethnic minority everyday life. Microaggressively, the label of "Cina" (as discussed later by another poem)has negatively colored the life of Chinese ethnic group, putting them into disadvantaged position in social interaction. 
From the discussion above, it may be concluded that both sides believe in superiority and authenticity of certain ethnicity — the Chinese and Non-Chinese_of which is actually merely fiction.

\section{The long journey: Too many differences}

The sixth metaphor is "journey" which compares life to a long journey in "Variety Brings Disaster" (6). The poem pessimistically sees life with diversity as a long winding journey because there are too many differences and competitions that will finally lead to war. The persona feels that the differences or diversities will cause conflicts and disasters because people compete one another with their own mission to complete. The conflicts will get worse even though people don't realize or wonder that "Time of war is closer" (line 8). The persona comes to this perspective because he/she has witnessed "the story" about the happenings where diverse people are at war. The microaggression presumably happens because people don't wonder (don't have the awareness) of the dangerous consequences of the pluralism that will end in a "war". Although for the time being everything seems alright, there is an intense worry that subtly terrorizes the persona of the coming war in the future life. The journey of living within a plural society in this context is never peaceful. The more diverse the society in this setting, the more dangerous life can be, and the closer the war to its occurrence.

\section{The flag: Missing of real empowering diversity}

The seventh metaphor is the changing colors of national flag "Red and White "into blue and black as elaborated in "Pluralism" (7). This signifies disappointments over the vanishing rich values of Indonesian plural societies (mostly forgotten) and also the changing attitudes (to forget) toward the richness and goodness of Indonesian diversity of specifically languages, tribes, and religions. There is a sense of forgetting the history of how great is the diversity used to be when people live in harmony although they are different in many ways. The persona's sense of nationalism and love of the country with all its diversity expressed through his repetition of "Indonesia, my beloved country" (lines 1, 5, 11)is placed in opposition to the present lack of diversity celebration leading him to a big disappointment. This situation shows the persona's experience of microaggression where he expects the country's celebration of the diversity (as represented by the national flag, supposedly stands side by side with the national slogan "Unity in Diversity" where diversity is considered as empowering) but in reality he sees people-he hyperbolically mentions all Indonesian! — forget about the value of diversity, disappointingly witnessing how the inverse happens. This sad reality for him is a microaggression since he is the only person celebrating diversity and therefore subtly marginalized in such a way that finally he cynically says of the national flag colors that "Our red become blue / And our white become black" (lines 10-11). Blue and black colors both signify the dark side of pluralism reality.

\section{Microaggressive Domination: Giant versus dwarf}

The eighth part of metaphors "giant" and "Small soldier" are used in You and Me (3) with reference to dominant majority and submissive minority as also elaborated in I Can't Deny (8). This power imbalance, leaving "no place for we" and "We will never become the true we" (You and Me, line 5, 12), has led to microaggresive domination. Unconsciously, the minority with their small soldier has no equal opportunities, and consequently gets no true peace because of the "war" (read discriminatory and marginalizing treatment or attitude from the majority). They live together but in false and failed unity.

This issue of minority and majority is also discussed in I Can't Deny (8) where pluralism is, on one hand, undeniable but, on the other hand, bad and "good" at the same time. The persona 
claims that the badness of pluralism is her submissive and disadvantaged position, showing how the majority is very powerful and dominating. The goodness is satirically addressed to the way the majority shows fear of the minority, spending much energy (thought, life, power, line 10) just to "push" the minority into marginal position while they do nothing. This unreasonable fear is sadly seen the goodness of pluralism for the minority, more of a kind of self-consolation in the bitterness of marginalization, and thus a form of microaggression. This is strengthened by

\section{Only propaganda: Teach and tell}

The ninth metaphor relates to the fact that unity in diversity slogan is merely propaganda without real practice in everyday life. In One (9), the slogan "We are one. One as a union, one in everything" (lines 3-4) is strongly criticized as "Nonsense" (line 4). This is proven by the real facts such as still labeling or calling "Cina" to the Chinese ethnic, laughing at different languages, not befriending the poor, killing other fellow "brothers" just because they have different beliefs, faiths, or perspectives. All slogans are only propagandas (teaching, telling) without real applications or practices. While calling or labeling someone with certain negative ethnic marker is more than just microaggression (but macroaggression), having subtler biased attitudes toward someone because she or he is different linguistically, socially, ethnically, etc. is a clear indication of microaggression. This issue on mere propaganda is also raised in another short poem Pluralism (11): "Indonesia, my beloved country/It's symbol, unity in diversity/But it is so different in reality/Will it stay like this for eternity?

\section{Questions: Are we better?}

The last metaphor discussed here is "question" in Questions (10) as a representation of how difficult it is to understand why people have judgment, narrow mind, and accusation over others without respect, acceptance, and love. The poem actually asks why the entire questions surface. The very surface of the questions itself is an indication that microaggression happens since the persona sees the common phenomena of judging, underestimating, looking down at others around her as if the proprietors have the right to do so. Ultimately, the poem raises the fundamental question whether we are better than others to exclusively have the right to judge them, signifying the existence of chauvinistic and fictitious attitudes that one ethnic group is better or the best. The fiction of a better ethnicity has led people have microaggressive attitudes in their judging view (way of seeing others as "the other", as lacking, weaker, outsider, lower, not as pure/authentic as, etc.) just as strongly criticized in another poem Different (12) that "No matter what I do, no matter what I say, no matter what I think, I am wrong because you considered me different".

\section{Concluding Remarks: Implications in Teaching (Literature)}

Based on the above discussion, it is apparently noticeable that beyond Indonesian pluralism reality lie these microaggressive attitudes and practices of fictitiously considering others as worse, different and the other. All these microaggressions are traced in the students' negative or ambiguous/neutral tones or attitudes toward pluralism in their seemingly simple and direct poems. The study of the poems has shown that microaggressions may take diverse unrealized forms, such as seeing difference as wrong or sinful, considering the "rainbow" of diversity as piteous, viewing intermingled mixtures of different backgrounds with ambiguous attitudes, the impossibility of having a real sense of "we" belonging, fictiveness of superior ethnicity and both sides of microaggression, disempowering diversities with too many differences, merely teaching and telling of diversity without modeling, surfacing of microaggressive domination, and questioning the fiction 
of authentic ethnicity. All issues have been proven to be the new faces of modern and subtle racism and chauvinism with their growing underground power to reject diversity.

In today's education, the knowledge and awareness of this diversity and its microaggression can provide a significant foundation for educators to set the right attitudes in embracing students and people of education from undeniably different backgrounds. Furthermore, literature and its updating teaching and learning may offer a rich medium in identifying subtle attitudes toward diversity, and thus learning and teaching the dynamics of pluralism in a more comprehensive (surface and depth) way, and finally leading the young into enlightened people with embracing attitudes toward any forms of diversity. More specifically, poetry—with its rich nature of spontaneity and contemplation and metaphorical expression-has given a more spacious creativity and possibility of revealing the subtle and hidden attitudes toward pluralism and other accompanying realities. The method used in this research is also suggested as an alternative method for teaching literature which involves students' active and creative responses toward their real life.

\section{Notes}

${ }^{i}$ There are at least two contexts where pluralism issue is highlighted such as in Indonesian national slogan Bhinneka Tunggal Ika (Unity in Diversity) since Indonesia's Independence 17 August 1945 as written in the Nation Symbol Garuda Pancasila and in the Ninth of Nine Priorities known as NawaCita (Nine Ideals) of today's JokoWidodo's leadersip stated as “To strengthen diversity and Indonesian social restoration through the policy of diversity education empowerment.

ii There are three common attitudes (literarily called 'tones') in expressing ideas or thoughts i.e. positive, negative, and neutral (see for example ...

\section{REFERENCES}

Arp, T.R. (1998). Perrine's Literature: Structure, Sound, and Sense. Orlando: Harcourt

Brace College Publishers.

Brett, R.L. \&Jones, A.R. (2005). Lyrical Ballads: Wordsworth and Coleridge. New York: Routledge.

Drury, J. (2006). The Poetry Dictionary. Ohio: Writer's Digest Book.

Fainsilber, L. \&Ortony, A. (1987). Metaphorical uses of language in the expression of emotions. Metaphor and Symbolic Activity 2 (4), 239-250.

Heryanto, A. (2014). Identity and Pleasure: The Politics of Indonesian Screen Culture. Singapore: NU Press.

------, (2015).Identitas “Asli” adalabFiksi.Kompas Daily, Sunday, 2 August 2015, p.13.

Kenndy, X.J. \&Gioia,D. (2005). Literature: An introduction to fiction, poetry, and drama. New York: PearsonLongman.

Modell, A.H. (2005). Emotional memory, metaphor, and meaning. PsychoanalyticInquiry 25.

Parvis, L. (2013).Understanding cultural diversity in today's complex world. Minneapolis: Embrace Publications \& Consulting, LLC.

Sue, D.W. (2010).Microaggressions in everyday life: Race, gender, and sexual orientation. New Jersey: John Wiley and Sons, Inc.

Utley, D. (2011). Intercultural Resource Pack: Intercultural communication resources for language teachers. Cambridge: Cambridge University Press. 


\section{Appendix}

Attachment: 12 Selected Poems

Pluracism (1) by Riki Rinaldi

We didn't know we are different

Until they said so

We didn't know what colors we belong to

Until they classified us unequivocally

We didn't feel any guilt when we say we are different

Until they said it is a sin

Who are they to us?

Telling us about this pluracism

When we even think that we are not different.

Pity Rainbow (2) byValerianaMulyani

People live in this one world.

One place, and one community

to live in unity,

to create peace.

We are one,

but we are apart.

Having a hope to be united,

but pluralism makes us to be separated.

We say diversity is pretty

Like different colors of a rainbow.

Yet our differences are pity.

Bring unaided conflicts.

You and Me (3)by Anita Dewi

We are all on the same ground

We are all united

but there are still you and me

not we.

There is no place for we.

Peace is just a left word

You, put your war on me

You against me.

Me, with my small soldier

And you, with your giant

Who can beat your giant?

We will never become the true we. 
I had A Friend (4) by AnselmaWidha P.

I had a friend

Once we went out for lunch,

Stood before a salad bar,

And put all kinds of fruit

And vegetables

Into a bowl,

Dressed them in three kinds of sauces,

And tossed them around,

So that the peas would all mingle among the others

And the corns, tomatoes, and watermelons

Be introduce to one another,

And so that they would all bathe

In the same amount of sauce.

All finished, my friend and I went back to our table

And sat to share that bowl of intermingled salad.

But ten my friend asked for an empty plate,

And carefully,

He picked up all the pretty peas

And put them on the empty plate,

"I don't like peas," he said.

"So why did you them into the bowl?" I asked.

He shrugged, "It seemed proper to take a bit all."

"And not improper to set them apart?"

He grinned, and shrugged again,

"I don't like peas," he said.

\section{Unity (5) by Sisca Veronica}

Being a Chinese sometimes is hard

Especially because we are minority

And it's also hard because I can't marry Indonesian

My parents said so

Even though they are handsome, kind, and rich

What a shame!

But it's alright

Differences give color to our country, Indonesia

As long as we forget prejudice and pride

Then we can be one and united

Believe me, we can!

\section{Variety Brings Disaster (6) by Devi Santoso}

Life is a long journey

Too many differences 
Try to compete

Until complete.

Hour by hour

The story begins

No one wonder

Time of war is closer.

Pluralism (7) by IkhsanAryoDigdo

Indonesia, my beloved country

Language, tribes, and religion

All of these are real in my country

But, most of people forget about it.

Indonesia, my beloved country

Language, tribes, and religion

Now are forgotten by all Indonesian

It is really a big disappointment.

Indonesia, my beloved country

Our red now become blue

And our white become black

Our pluralism is missing now.

\section{Can't Deny (8) by Sara Vanessa}

I can't deny if I live in the world with pluralism

Is it good? Yes

Is it bad? Yes

Good for me to see the positive of pluralism

Unlucky me to experience the negative of pluralism.

I, personally think, am minority, submissive

On the other hand, also powerful

Why?

Because they, who say that, are majority, dominant, Spend their thought, life, power,

To push I.

Why are they so afraid?

While I do nothing.

One (9) by Sekar A. Utami

This is where I am, living in a place

Where people say, "We are one".

One as a union, one in everything.

Nonsense.

Why do you call them "Cina"?

Why are you laughing when they speak different dialect?

Why can't be friends with me, who have nothing?

Why killing our brothers? 
89 Microaggression and Diversity: Tracing Indonesian University Students' Attitudes toward

Pluralism through Metaphorical Creative Expressions

When they have their perspective, their beliefs, their faith.

You may teach me that we are one. But you can't tell me that we are the same.

We are one, in different ways.

Questions (10) by Diana Mariska

Who are we?

Who are we to judge?

Who are we to narrow our eyes?

Who are we to point our fingers?

Can't we just accept each other for who we are?

Can't we just look at each other respectfully, and more importantly, lovingly?

Can't we just hold hands together in harmony?

Do we have the right to look at others with disdain?

Are you given that right?

I get one more question to make us sick of ourselves

Are we better?

Pluralism (11) by Kevin Setyawan

Indonesia, my beloved country

It's symbol, unity in diversity

But it is so different in the reality

Will it stay like this for eternity?

Different (12) by Melissa Sylviani

No matter what I do

No matter what I say

No matter what I think

I am wrong

Because you considered me different.

Andreas Akun \& Wiwik Andreani teach in the English Department, Faculty of Humanities, Bina Nusantara University, Indonesia 